\title{
Research on Self-exciting Air-core Pulsed Alternator Considering Armature Reaction
}

\author{
Wenchao Li ${ }^{1,2}$, Ying Zhang ${ }^{1,2}$, Zehui Liu ${ }^{1,2}$, Danni Luo ${ }^{1,2}$, Youlong Wang ${ }^{1,2,3}$ and Yaohong Sun ${ }^{1,2^{*}}$ \\ ${ }^{1}$ Institute of Electrical Engineering, Chinese Academy of Sciences, Beijing, 100190, China \\ ${ }^{2}$ University of Chinese Academy of Sciences, Beijing, 100049, China \\ ${ }^{3}$ Advanced Electromagnetic Drive Technology Research Center, Institute of Electrical Engineering, Chinese Academy of \\ Sciences, Jinan, Shandong, 250013, China
}

\begin{abstract}
Compared with the traditional synchronous generator with iron core structure, air-core pulse alternator usually adopts self-excitation to establish a higher field current to meet its demand for high flux density. In this paper, the topology of the self-exciting rectifier is determined to be the full bridge rectifier by discussing the respective application scope of the full bridge and the half wave rectifier. Considering the armature reaction, the self-excitation process and the coupling relationship between the field winding and the armature winding are analyzed. According to the commutation overlap angle, the equivalent circuits of different states are carried out, and the instantaneous expressions of field current and armature current are deduced, which lays a foundation for the following phase control research.
\end{abstract}

\section{Introduction}

Compared with the current more mature capacitor energy storage pulse power supply, air-core pulse alternator energy storage is a form of inertial energy storage. It not only has high power density, but also has exceeding high energy storage density [1], therefore, it is well suited to compact pulse power supply. However, its air-core structure makes the magnetic permeability in the magnetic circuit almost vacuum, it must have a higher excitation power to meet its demand for high magnetic flux density. Nowadays, the excitation methods of the pulse alternators include permanent magnet, separate excitation and self-excitation. The intensity of the magnetic field excited by the permanent magnet excitation method is limited, which is not suitable for the excitation of air-core structures; the additional excitation power supply (such as capacitor) required for separate excitation leads to a large increase in the system volume; therefore, researchers are more tend to adopt selfexciting method to establish the required field current. the self-exciting topology is shown in figure 1. Selfexcitation is to use the alternator's own energy for excitation. First, a small seed current into the field winding is inject to establish a lower excitation magnetic field, so that the armature winding generates an induced voltage, and then the $\mathrm{AC}$ armature current is rectified to the direct current then discharges the field winding to increase the field current, forming a positive feedback process, thereby quickly establishing the required field current.

Based on the current research trend of air-core pulse alternator, this article focuses on the structure of rotating-field and two pairs of poles, and assumes that the armature windings are uniformly distributed, and the no-load air gap magnetic field is sinusoidally distributed along the circumference [2].

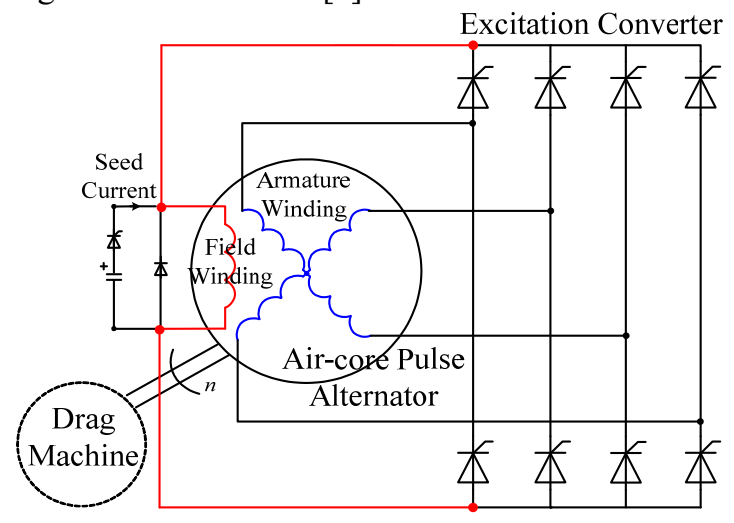

Fig. 1. Self-exciting topology.

\section{Determination of topology of self- excitation magnetic rectifier}

In order to explore the topology suitable for the selfexciting rectifier, the following simulation analysis is carried out:

As shown in figure 2, the sinusoidal AC source with uniform phase (four-phase) and fixed amplitude uses full bridge and half-wave rectification to discharge the large inductive impedance load $\left(Z_{\text {load }}>>Z_{\mathrm{i}}\right)$ and the shortcircuit load. Comparing the discharge current of two rectification methods under the same load, i. e. Ifull_large, $I_{\text {half_large }}$ and $I_{\text {full_short }}, I_{\text {half_short. }}$ This paper conducts qualitative analysis, the voltage source is set as $333.3 \mathrm{~Hz}$

\footnotetext{
* Corresponding author: yhsun@mail.iee.ac.cn
} 
frequency and $1 \mathrm{~V}$ amplitude. $Z_{\mathrm{i}}=4 \mathrm{mH}-2.1 \mathrm{~m} \Omega$; $Z_{\text {load }}=1.5 \mathrm{mH}-70 \mathrm{~m} \Omega$.
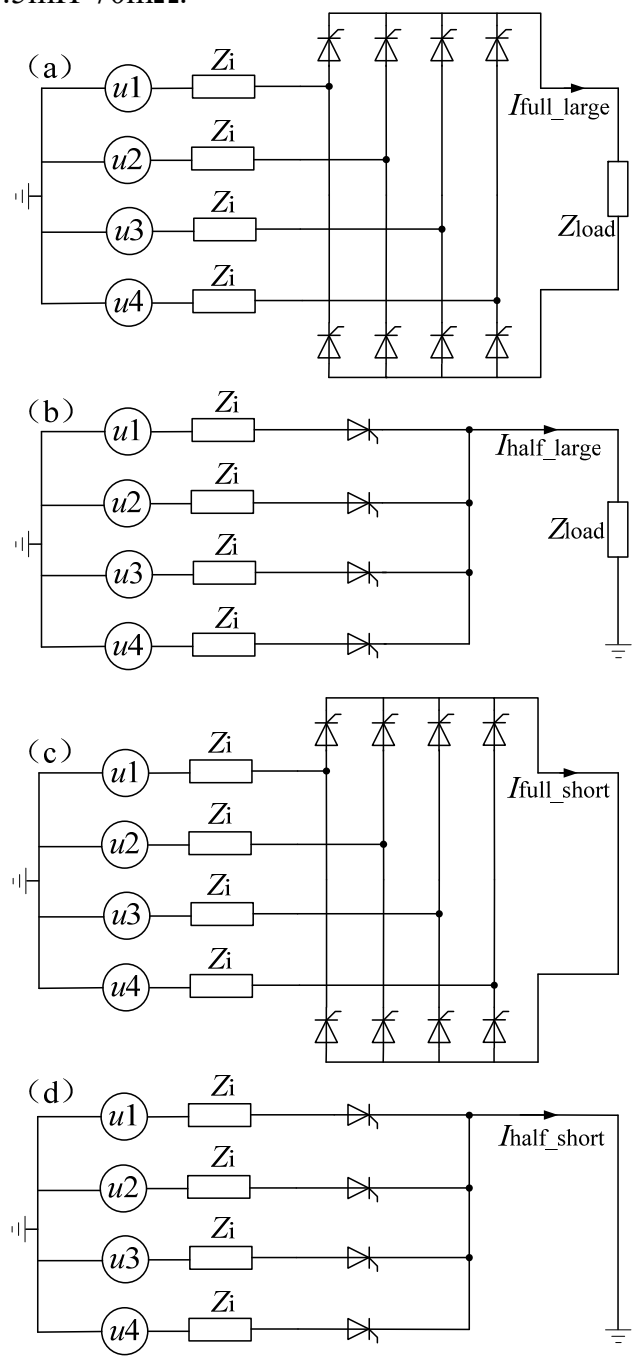

Fig. 2. Different rectification methods, different load discharge topologies. (a) Full bridge - Large inductive. (b) Half - Large inductive. (c) Full bridge - Short. (d) Half - Short.
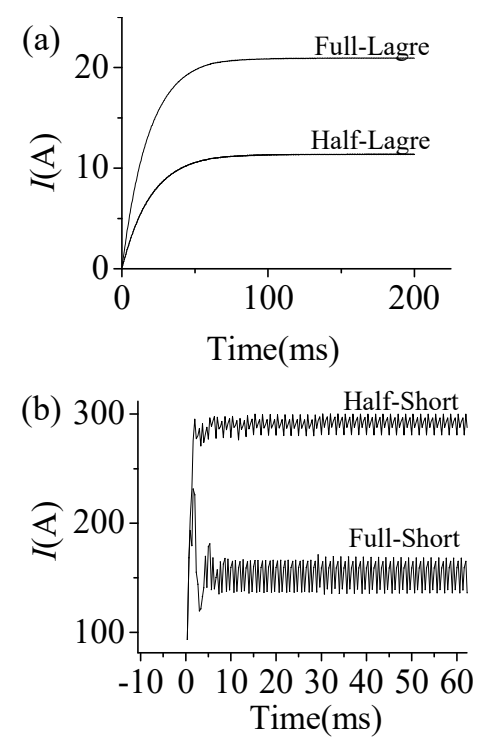

Figure 3. Comparison of full bridge and half wave current. (a)Large inductive. (b) Short.
It is found that the full-bridge rectifier discharge current is larger when discharging the large inductive impedance load, and the half-wave rectification discharge current is larger when discharging the shortcircuit load. The simulation result is shown in figure 3 .

Self-exciting magnetic discharge is to discharge the field winding, and the impedance of the field winding is much larger than that of the armature winding. It can be considered that the self-excitation discharge process is the process of discharging a large inductive impedance load, as shown in figure 3(a) Therefore, the full-bridge topology builds up the field current faster than the halfwave topology.

\section{Mathematical model of air-core pulse alternator considering armature reaction}

\subsection{Armature reaction of air-core pulse alternator}

For the rotating field synchronous motor, the armature (stator) winding is open when it is running at no-load, and there is only the rotor field that rotates synchronously in the motor. However, once the motor is running with a load, a current appears in the armature winding, which generates armature reaction magnetic field. This magnetic field is bound to affect the field current. Therefore, it can be understood that the armature current has an effect on the field current. In addition, the process makes the armature current affect the field current in the electrical structure, and the field current affects the armature current through the excitation magnetic field [3].

\subsection{Mathematical model}

The mutual inductances between the field winding and each phase armature winding is [4-5]:

$$
m_{\mathrm{fx}}=M_{\mathrm{f}} \cos (\theta-0.5(x-1) \pi)
$$

Where $x=1,2,3,4$ represent phase $1,2,3$ and 4 respectively; $M_{\mathrm{f}}$ is the amplitude of the mutual inductance between the armature winding and the field winding. $\theta=\omega t+\theta_{0}$ is the angle between the armature winding of phase 1 and the axis of the field winding, $\theta_{0}$ is the initial angle value, $t$ is time. According to the KVL law, the output voltage of each phase armature winding of the alternator is:

$$
\left\{\begin{array}{l}
u_{\mathrm{x}}=e_{\mathrm{x}}+u_{\mathrm{m}-\mathrm{x}}-L_{\mathrm{self}} i_{\mathrm{x}}{ }^{\prime}-R_{\mathrm{self}} i_{\mathrm{x}},(x=1,2,3,4) \\
u_{\mathrm{m} 1}=-\left(M_{12} i_{2}{ }^{\prime}+M_{13} i_{3}{ }^{\prime}+M_{12} i_{4}{ }^{\prime}\right) \\
u_{\mathrm{m} 2}=-\left(M_{12} i_{1}^{\prime}+M_{12} i_{3}{ }^{\prime}+M_{13} i_{4}{ }^{\prime}\right) \\
u_{\mathrm{m} 3}=-\left(M_{13} i_{1}^{\prime}+M_{12} i_{2}{ }^{\prime}+M_{12} i_{4}{ }^{\prime}\right) \\
u_{\mathrm{m} 4}=-\left(M_{12} i_{1}^{\prime}+M_{13} i_{2}{ }^{\prime}+M_{12} i_{3}{ }^{\prime}\right)
\end{array}\right.
$$

Where $u_{\mathrm{m}_{\mathrm{x}}}$ is the mutual induction electromotive force of other phase armature windings to phase $\mathrm{x}$; $i_{\mathrm{x}}$ is 
armature current of phase $\mathrm{x}$; $L_{\text {self }}$ is the self-inductance of the armature winding; $R_{\text {self }}$ is the resistance value of the armature winding. $M_{12}$ is the mutual inductance of the adjacent phase armature windings; $M_{13}$ is the mutual inductance between the interval phase armature windings.

According to the principle of electrical machinery, the no-load electromotive force of each phase armature winding can be derived as:

$$
e_{\mathrm{x}}=E \sin (\theta-0.5(x+1) \pi)
$$

Where $E=\omega M_{\mathrm{f}} \quad i_{\mathrm{f}}$ is the amplitude of no-load electromotive force; $i_{\mathrm{f}}$ is the field current. The voltage at both ends of field winding is:

$$
\left\{\begin{array}{l}
u_{\mathrm{f}}=u_{\mathrm{m}_{-} \mathrm{f}}+L_{\mathrm{f}} i_{\mathrm{f}}{ }^{\prime}+i_{\mathrm{f}} R_{\mathrm{f}} \\
u_{\mathrm{m}_{-} \mathrm{f}}=-\sum_{x=1}^{4}\left(m_{\mathrm{fx}} i_{\mathrm{x}}\right)^{\prime}
\end{array}\right.
$$

Where $u_{\mathrm{m}} \mathrm{f}$ is mutual inductance voltage of armature winding to field winding. $L_{\mathrm{f}}$ is the self-inductance of the field winding; $R_{\mathrm{f}}$ is the resistance value of the field winding.

\section{Theoretical analysis}

The decrease in speed during the excitation process is almost negligible, therefore the angular velocity $\omega$ is regarded as a constant in the derivation process. For the self-excitation process of even-numbered phase motors, when full-bridge rectification is used, it can be known from the symmetry that the output voltages and armature currents of phase 1 and phase 3, phase 2 and phase 4 are mutually opposite.

\subsection{Commutation overlap angle and state classification}

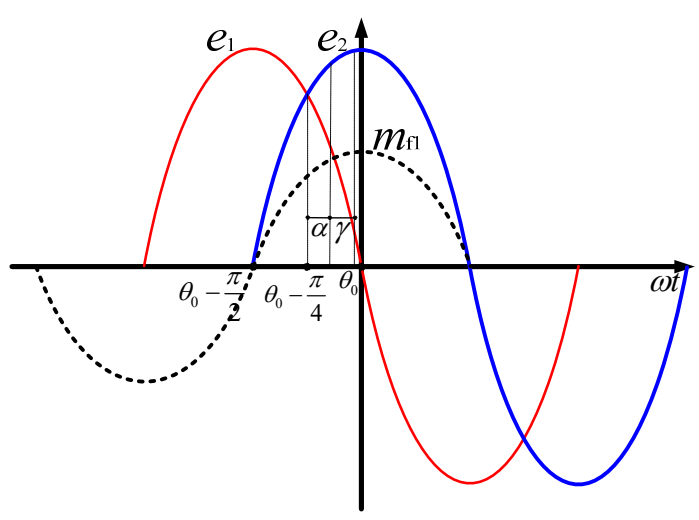

Fig. 4. Self-exciting topology.

Where $\alpha(0<\alpha<0.5 \pi)$ is excitation firing angle; $\gamma$ is commutation overlap angle. According to the influence of $\mathrm{AC}$ circuit inductance on rectification characteristics, $\gamma$ is [6]:

$$
\gamma=\alpha+\arccos \left(\cos (\alpha)-\frac{L_{\text {self }}+M_{13}}{M_{\mathrm{f}} \sin (0.25 \pi)}\right)
$$

From the perspective of armature winding, there are eight discharge states of the four-phase alternator, as shown in table 1.

Table 1. Four-phase alternator discharge status - Armature winding.

\begin{tabular}{|c|c|c|c|c|c|c|c|c|}
\hline Status & $\mathbf{1}$ & $\mathbf{2}$ & $\mathbf{3}$ & $\mathbf{4}$ & $\mathbf{5}$ & $\mathbf{6}$ & $\mathbf{7}$ & $\mathbf{8}$ \\
\hline $\begin{array}{c}\text { Discharge } \\
\text { Circuit }\end{array}$ & $1 \rightarrow 3$ & $\begin{array}{c}1 \rightarrow 3 \\
2 \rightarrow 4\end{array}$ & $2 \rightarrow 4$ & $\begin{array}{c}2 \rightarrow 4 \\
3 \rightarrow 1\end{array}$ & $3 \rightarrow 1$ & $\begin{array}{c}3 \rightarrow 1 \\
4 \rightarrow 2\end{array}$ & $4 \rightarrow 2$ & $\begin{array}{c}4 \rightarrow 2 \\
1 \rightarrow 3\end{array}$ \\
\hline $\begin{array}{c}\text { Duration } \\
(\omega \mathrm{t})\end{array}$ & $0.5 \pi-\gamma$ & $\gamma$ & $0.5 \pi-\gamma$ & $\gamma$ & $0.5 \pi-\gamma$ & $\gamma$ & $0.5 \pi-\gamma$ & $\gamma$ \\
\hline
\end{tabular}

The arrow in table 1 indicates the direction of current flow. Due to the symmetry of the phases, the excitation effect of the states 1-2, states 3-4, states 5-6 and states 78 on the field winding is the same, If the initial point of the state is regarded as 1 , and only its growth rate is concerned, it can be regarded as four repeated processes, and each pulse wave growth rate is the same, that is, the pulse frequency of the field current should be four times the electrical frequency of the armature current. Therefore, from the perspective of the field winding, there are two states of the four-phase alternator when the full bridge rectifier discharge is adopted, as shown in Table 2. The equivalent circuits of the two states are shown in figure 5 .
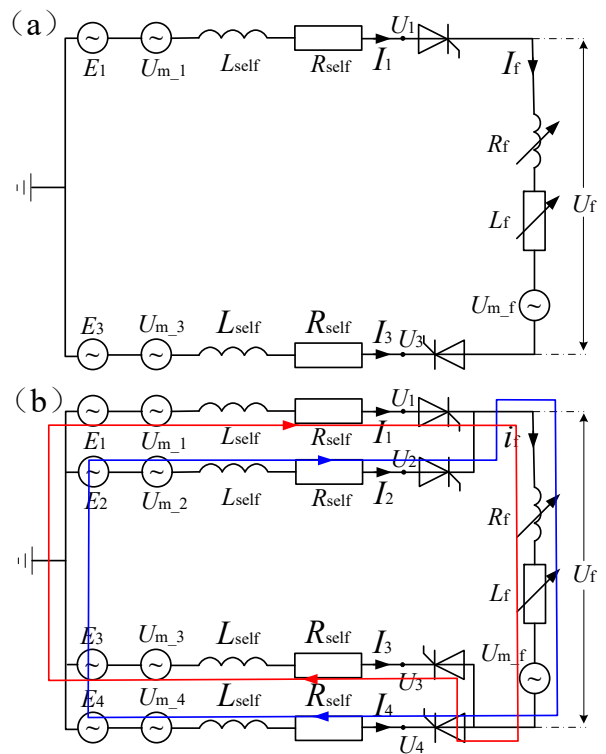

Fig. 5. Equivalent circuits (a) State 1 (field winding). (b) State 2 (field winding).

Table 2. Four-phase alternator discharge status - Field winding.

\begin{tabular}{|c|c|c|}
\hline Status & $\mathbf{1}$ & $\mathbf{2}$ \\
\hline $\begin{array}{c}\text { Discharge } \\
\text { Circuit }\end{array}$ & One Circuit & Two Circuit \\
\hline $\begin{array}{c}\text { Duration } \\
(\omega \mathrm{t})\end{array}$ & $0.5 \pi-\gamma$ & $\gamma$ \\
\hline
\end{tabular}




\begin{tabular}{|c|c|c|}
\hline Phase & $\left(\theta_{0}+\alpha+\gamma-0.75 \pi+0.5 \mathrm{n} \pi\right.$, & $\left(\theta_{0}+\alpha-0.25 \pi+0.5 \mathrm{n} \pi\right.$, \\
$\left.\theta_{0}+\alpha-0.25 \pi+0.5 \mathrm{n} \pi\right)$, & $\left.\theta_{0}+\alpha+\gamma-0.25 \pi+0.5 \mathrm{n} \pi\right)$, \\
Angle & $(\mathrm{n}=12 \ldots)$ & $(\mathrm{n}=12 \ldots)$ \\
\hline
\end{tabular}

\subsection{Instantaneous expressions}

The equivalent circuits of the two states are shown in figure 5. To facilitate the solution, the value of the field current at the initial moment of each state is regarded as 1. State 1 (field winding): according to figure 5 (a), it can be concluded:

$$
\left\{\begin{array}{l}
u_{\mathrm{f}}(t)=u_{1}(t)-u_{3}(t)=u_{2}(t)-u_{4}(t) \\
i_{\mathrm{f}}(t)=i_{1}(t)
\end{array}\right.
$$

Simultaneous formulas (2), (4) and (6) can obtain the instantaneous expression of field current and armature current as: $i$

$$
\begin{gathered}
i_{\mathrm{f}}(t)=e^{\frac{4 m_{\mathrm{f}}-\left(R_{\mathrm{f}}+2 R_{\mathrm{felf}}\right) t}{L_{\mathrm{f}}+4\left(L_{\mathrm{self}}-M_{13}\right)}} \\
\left\{\begin{array}{l}
i_{1}(t)=-i_{3}(t)=i_{\mathrm{f}}(t) \\
i_{2}(t)=-i_{4}(t)=0
\end{array}\right.
\end{gathered}
$$

State 2 (field winding): according to figure 5 (b), it can be concluded:

$$
\left\{\begin{array}{l}
i_{1}(t)=-i_{3}(t)=i_{\mathrm{f}}(t) \\
i_{2}(t)=-i_{4}(t)=0
\end{array}\right.
$$

Simultaneous formulas (2), (4) and (9), and simplified into the first-order differential equation, we can get:

$$
L_{\mathrm{f}} i_{\mathrm{f}}{ }^{\prime}+\left(R_{\mathrm{f}}+R_{\text {self }}-2\left(m_{\mathrm{f} 1}+m_{\mathrm{f} 2}\right)^{\prime}-\left(\frac{m_{\mathrm{f} 1}-m_{\mathrm{f} 2}}{L_{\mathrm{self}}-M_{13}}\right)^{\prime} i_{\mathrm{f}}=C\left(m_{\mathrm{f} 1}-m_{\mathrm{f} 2}\right)^{\prime}\right.
$$

$$
\left\{\begin{array}{l}
i_{1}(t)=-i_{3}(t)=i_{\mathrm{f}}(t) \\
i_{2}(t)=-i_{4}(t)=0
\end{array}\right.
$$

Where

$$
C=\left.\left(1-\frac{\left(m_{\mathrm{f} 1}-m_{\mathrm{f} 2}\right) i_{\mathrm{f}}}{L_{\mathrm{self}}-M_{13}}\right)\right|_{\omega t=\theta_{0}+\alpha-0.25 \pi} \quad,
$$

$C_{1}=\left.\left(\frac{1}{2}-\frac{\left(m_{\mathrm{f} 1}-m_{\mathrm{f} 2}\right)}{L_{\text {self }}-M_{13}}\right) i_{\mathrm{f}}\right|_{\omega t=\theta_{0}+\alpha-0.25 \pi} \quad, \quad$ This $\quad$ is $\quad$ a transcendental equation, and its analytical solution cannot be obtained directly, therefore, the first-order difference method can be used to solve its numerical solution through matlab.

\section{Simulation analysis}

According to the mathematical model in Chapter 3, Matlab / Simulink is used to build the simulation model. The simulation parameter settings are shown in Table 3 .
It can be seen from figure 6 that the field current fluctuates and rises during the self-excitation process, and the fluctuation frequency is four times that of the the armature current. Amplify one of the pulse waves locally, set the starting point of the fluctuation to 1 , and compare it with the theoretical derivation as shown in figure 7.

Table 3. Simulation parameter

\begin{tabular}{|c|c|}
\hline Parameter & Value \\
\hline$M_{\mathrm{fx}}(\mu H)$ & 40 \\
\hline$L_{\text {self }}(\mu H)$ & 4 \\
\hline$L_{\mathrm{f}}(m H)$ & 1.5 \\
\hline$M_{12}(\mu H)$ & 0 \\
\hline$M_{13}(\mu H)$ & -4 \\
\hline$R_{\text {self }}(m \Omega)$ & 2.1 \\
\hline$R_{\mathrm{f}}(m \Omega)$ & 70 \\
\hline$\omega(\operatorname{rad} / \mathrm{s})$ & 2093.3 \\
\hline$I_{\text {f_seed }}(\mathrm{kA})$ & 3.54 \\
\hline$I_{\mathrm{f} \_ \text {end }}(\mathrm{kA})$ & 30 \\
\hline
\end{tabular}

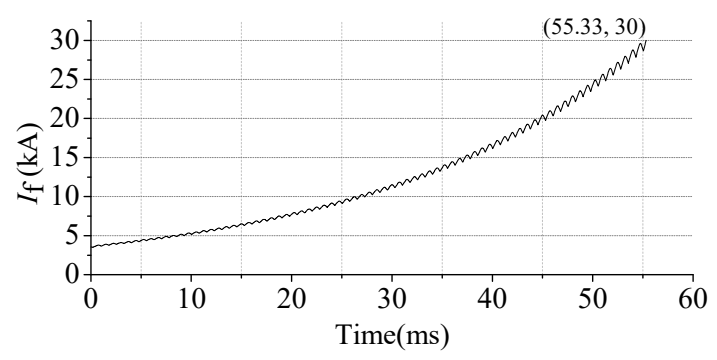

Fig. 6. Simulation waveform of field current

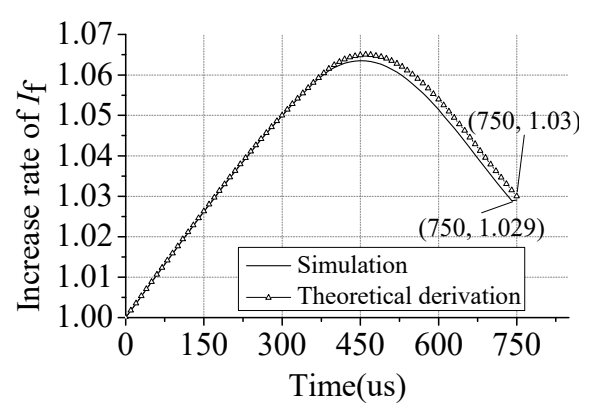

Fig. 7. Comparison of theoretical derivation and simulation

By comparison, it is found that they are basically the same. The simulation results of single-pulse wave growth rate and self-exciting time are $1.029 \mathrm{~ms}$ and $55.33 \mathrm{~ms}$, respectively. The theoretical derivation result of single-pulse wave growth rate is 1.03 , which requires at least 73 pulse waves to reach $30 \mathrm{kA}$ by calculation. 
The theoretical derivation result of self-exciting time is $54.75 \mathrm{~ms}$, and the difference of self-exciting time between the two is $1 \%$.

\section{Conclusion}

In this paper, the self-excitation process of four-phase pulse alternator considering the armature reaction is introduced. The following conclusions are reached:

1) In the self-excitation regime, the full bridge topology can build up the field current faster than the half wave topology.

2) The field current in the self-excitation process can be divided into two states, and the pulse frequency of the excitation current is four times than the armature current. In addition, the proportions of the two states are calculated according to the commutation overlap angle.

3) The expressions of the field current and the armature current are deduced, the simulation model is built according to the state equation, and the theoretical deduction results are compared with the simulation results, and the two are basically the same.

\section{References}

1. M.L. Spann, S.B. Pratap, M.D. Werst, et al., The self-excitation process in electrical rotating machines operating in pulsed power regime, IEEE Trans. Magn. 39, 1, 529-537 (2001)

2. C.Y. Ye, K.X. Yu, H. Zhang, et al., Optimized design and simulation of an Air-Core pulsed alternator, IEEE Tran. Plasma Sci. 43, 5, 1405-1409 (2015)

3. G.W. Fan, Principle and application technology of synchronous motor (PP Press, Beijing, 2014)

4. X.F. Xie, K.X. Yu, C.Y. Ye, et al., Transient analysis of Air-Core pulsed alternators in SelfExcitation mode, IEEE Tran. Plasma Sci. 43, 5, 1415-1420 (2015)

5. K.X. Yu, C.Y. Ye, Y. Pan, ICEMS, (2015)

6. J. Chen, Y. Kang, Power Electronics (HE Press, Beijing, 2012) 